Dikirim: 19 September 2016 Diterbitkan: 1 Maret 2017

\title{
Determinan konsumsi mie instan pada mahasiswa universitas Sriwijaya
}

\section{Determinants of instant noodles consumption among students in Sriwijaya university}

Vera Utami ${ }^{1}$, Yayi Suryo Prabandari ${ }^{1}$, Susetyowati ${ }^{2}$

\begin{abstract}
Purpose: This study aimed to explore the factors that influence the instant noodle consumption among students in Sriwijaya university. Methods: This research was a qualitative study with phenomenological approach. Data were collected through in-depth interviews with 20 informants. The sampling technique was purposive sampling. The data collection was conducted from June-September 2015. Results: This study showed that individual factors are the most influential factors, including time constraints, taste, aroma, and prices which were supported by the social environmental factors, including the pattern of family relationships and patterns of friendship. Physical environmental factors included easy access and sufficient availability of instant noodles and macro environmental factors including the lack of campus policies, social norms in the society as well as the advertising effect on the consumption of instant noodles with new flavors. Conclusion: Students receive advice about diet from educational promotional efforts through seminars and social media.
\end{abstract}

Keywords: consumption of instant noodles; student

\footnotetext{
${ }^{1}$ Departemen Perilaku Kesehatan, Lingkungan dan Kedokteran Sosial, Fakultas Kedokteran, Universitas Gadjah Mada (Email: amie.utami0705@gmail.com)

${ }^{2}$ Departemen Gizi Kesehatan, Fakultas Kedokteran, Universitas Gadjah Mada
} 


\section{PENDAHULUAN}

Penyakit tidak menular yang biasa dikenal sebagai penyakit kronis merupakan penyakit yang mempunyai durasi yang panjang dan perkembangan yang umumnya lambat. Penyakit tidak menular sering dikaitkan dengan kelompok usia yang lebih tua, tetapi sekarang ini justru cenderung diderita oleh orang yang berusia di bawah 40 tahun. Semua kalangan usia terutama anak-anak dan remaja rentan terhadap faktor-faktor risiko yang berkontribusi terhadap penyakit tidak menular seperti pola makan yang tidak sehat (1).

Salah satu makanan yang tidak sehat dan sangat digemari oleh masyarakat terdapat pada golongan makanan olahan (2). Mie instan sering dikritik sebagai makanan yang tidak sehat atau digolongkan sebagai junk food. Hal ini dikarenakan dalam sekali penyajian mie instan umumnya mengandung lemak dan natrium yang tinggi, namun rendah serat, vitamin dan mineral (3). Pola konsumsi mie instan mempunyai pengaruh positif terhadap obesitas abdominal dan hiperkolesterolemia (4). Konsumsi mie instan lebih dari 2 bungkus dalam seminggu berhubungan dengan peningkatan sindrom metabolik yang tinggi pada wanita. Pola konsumsi mie instan dapat ber- kontribusi terhadap pola makan (5). Konsumsi mie instan yang tinggi cenderung diiringi juga dengan konsumsi makanan fast food lain yang tinggi. Konsumen yang mengonsumsi mie instan cenderung lebih sedikit mengonsumsi buah dan sayuran (6).

Mie instan telah menjadi makanan yang diakui secara internasional. Konsumsi mie instan terus meningkat di seluruh dunia, terutama di negara -negara Asia (7). Hal ini dapat dilihat dari penjualan mie instan tertinggi yang berada di negara Cina pada tahun 2013, yang mencapai 46,22 miliar bungkus. Indonesia merupakan negara tertinggi kedua setelah Cina dalam mengonsumsi mie instan, dengan jumlah penjualan mie instan pada tahun 2013 mencapai 14,9 miliar bungkus (8).

Data Susenas 2013 menunjukkan bahwa rata-rata konsumsi mie instan selama seminggu mengalami peningkatan dari bulan September 2012, yakni 0,016/porsi menjadi 0,025/porsi pada bulan Maret 2013 (9). Makanan jadi olahan dari tepung, termasuk mie instan, dicurigai mengandung bahan atau lapisan lilin dan bahan pengawet yang dapat menyebabkan risiko kesehatan. Rata-rata penduduk Indonesia berperilaku mengonsumsi mie instan. Sebanyak 1 dari 10 penduduk mengonsumsi mie instan $\geq 1$ kali per hari. Sumatera Selatan merupakan provinsi tertinggi kedua dengan penduduk yang mengonsumsi mie instan lebih dari 1 kali per hari, di atas rata-rata nasional, yaitu sebesar 10,1\%. Proporsi penduduk yang berusia lebih dari 10 tahun yang mengonsumsi mie instan sebanyak 18,2\% di Provinsi Sumatera Selatan (10).

Konsumsi mie instan tertinggi pada usia 20-49 tahun dan berada pada tingkat pendidikan yang lebih tinggi dari sekolah menengah atas (3). Pola konsumsi mie instan cenderung lebih disukai oleh orang dengan tingkat pendidikan dan tingkat pendapatan yang tinggi (4). Peningkatan aktivitas fisik, kehidupan sosial dan kesibukan cenderung mengakibatkan mahasiswa mengonsumsi makanan yang tidak sehat (11). Hal ini perlu dijadikan perhatian karena konsumsi mie instan dapat menuntun mahasiswa mengonsumsi lemak, energi dan natrium yang tinggi (3). Sebagai upaya untuk mengkaji kebutuhan, penelitian kualitatif diperlukan untuk mengetahui faktor yang memengaruhi perilaku makan, terutama perilaku konsumsi mie instan pada mahasiswa dengan menggunakan model story (12). Penelitian ini bertujuan untuk menggali gambaran faktor yang memengaruhi perilaku konsumsi mie instan pada mahasiswa.

\section{METODE}

Penelitian ini merupakan penelitian kualitatif dengan pendekatan fenomenologi, dilakukan di Universitas Sriwijaya Sumatera Selatan pada bulan Juni-September 2015. Informan utama penelitian adalah mahasiswa dan mahasiswi yang tinggal bersama orang tua dan yang tidak tinggal bersama orang tua, yang mengonsumsi mie instan dengan frekuensi 1 kali selama 24 jam terakhir dan $\geq 2 \mathrm{x}$ seminggu sebelum penelitian, dengan rentang usia 18-22 tahun. Informan pendukung terdiri dari pemilik kantin dan pengelola kantin. Total informan pada penelitian ini berjumlah 20 orang yang terdiri dari 3 orang mahasiswa yang tinggal bersama orang tua, 6 orang mahasiswa yang tinggal di rumah kos, 2 orang mahasiswi yang tinggal bersama orang tua, 6 orang mahasiswi yang tinggal di rumah kos, 2 orang pemilik kantin dan 1 orang pengelola kantin.

Instrumen penelitian ini adalah panduan wawancara mendalam yang berisi pertanyaan mengenai gambaran perilaku konsumsi mie instan dan gambaran faktor yang memengaruhi. Selain panduan, peneliti menggunakan alat bantu rekam serta buku catatan untuk membantu mengumpulkan data selama pe- nelitian berlangsung.

Metode analisis data adalah dengan analisis konten. Peneliti membuat transkrip verbatim dari hasil 
wawancara dengan informan dan membuat catatan terkait temuan. Selanjutnya, peneliti membuat koding dengan software opencode dan mengumpulkan semua koding untuk selanjutnya dikategorikan. Peneliti menemukan pola kesamaan menjadi inti kategori dan melakukan interpretasi terhadap informasi, penyajian data dan menarik kesimpulan dalam bentuk laporan penelitian. Untuk menjamin keabsahan data, peneliti melakukan triangulasi waktu dan triangulasi sumber.

\section{HASIL}

Perilaku konsumsi mie instan. Kebiasaan makan mahasiswa menjadi tidak teratur dan berkurang sejak kuliah dikarenakan peningkatan aktivitas perkuliahan menyebabkan mahasiswa cenderung mengonsumsi mie instan. Mahasiswa mengungkapkan bahwa terdapat perubahan perilaku konsumsi mie instan yang meningkat pada saat awal kuliah dan ada yang menjadi kebiasaan sampai saat ini. Hal ini disebabkan oleh kepadatan jadwal kuliah, banyak tugas perkuliahan dan ketidaktahuan mahasiswa baru mengenai tempat makan di sekitar kampus. Mie instan lebih sering dijadikan sarapan karena keterbatasan waktu di pagi hari. Jumlah porsi konsumsi mie instan pada laki-laki lebih tinggi dibandingkan perempuan.

Faktor individu. Faktor individu yang paling berpengaruh terhadap kebiasaan konsumsi mie instan yang meliputi kendala waktu, harga, praktis, rasa lapar, aroma mie instan yang khas, rasa yang enak dan hobi. Informan mengakui mengetahui bahan berbahaya, penyakit yang ditimbulkan dan jarak mencerna mie instan. Informan menyatakan ketidaksetujuan terhadap konsumsi mie instan berlebihan, dikarenakan mie instan tidak baik untuk kesehatan. Informan juga sudah pernah mencoba membuat aturan untuk membatasi konsumsi mie instan, tetapi informan tidak terlalu yakin dapat mematuhi aturan yang sudah dibuat. Informan mengalami kesulitan untuk membatasi konsumsi. Hasil wawancara menunjukkan bahwa faktor individu yang mendukung untuk mengonsumsi mie instan meliputi kepadatan aktivitas perkuliahan, keuangan yang tidak memadai, tingkat kepraktisan mie instan yang ditunjang dengan rasa lapar.

"Mungkin karena kesibukan kuliah, atau kesibukan organisasi, sehingga pulang terlalu sore”

(MK, 22 tahun, mahasiswa)
Gambaran faktor lingkungan sosial yang memengaruhi perilaku konsumsi mie instan. Faktor lingkungan sosial yang memengaruhi meliputi pola hubungan keluarga dan pola pertemanan. Keluarga memegang peranan penting dalam hal kebiasaan makan mahasiswa. Informan mengakui bahwa sudah terbiasa mengonsumsi mie instan sejak kecil, sehingga menjadi kebiasaan tersendiri hingga sekarang. Keluarga juga memegang peranan dalam pembatasan konsumsi mie instan pada informan, seperti informan mengakui membatasi konsumsi mie instan apabila orang tua mengontrol konsumsi mie instan. Namun, ada juga orang tua yang tidak melarang konsumsi mie instan dan menganjurkan untuk mengonsumsi mie instan karena takut informan kelaparan. Hal ini dikarenakan sudah terbiasa sejak dulu, serta orang tua juga menyediakan stok mie instan.

Pola pertemanan juga memegang peranan cukup penting dalam perilaku konsumsi mie instan. Beberapa informan terpaksa mengonsumsi mie instan karena tidak enak dengan teman-teman, selain itu terdapat rasa kebersamaan saat mengonsumsi mie instan, apalagi jika keuangan sedang menipis. Selain itu, konsumsi mie instan menjadi lebih sering saat sedang ada tugas kuliah yang harus dikerjakan bersama teman.

"Iya, kadang-kadang terpaksa mbak, mau tidak mau, teman sudah memasak. Apalagi bila kita sedang tidak ada uang dan adanya itu, mau tidak mau ya sudahlah. Bukan dari yang haram, jadi mau tidak mau dimakan.”

(DSK, 21 tahun, mahasiswa)

Faktor lingkungan fisik. Akses untuk membeli mie instan sangat terjangkau bagi informan. Hampir semua warung yang berada dekat informan menjual mie instan, sehingga mempermudah informan untuk membeli mie instan, baik yang sudah dimasak maupun yang belum dimasak.

\section{"Iya dekat, karena warungnya ada di depan rumah."}

(H, 21 tahun, mahasiswi)

Selain hal tersebut, warung yang menjual nasi lebih sering tutup pada sore hari, yang menyebabkan informan lebih sering makan mie instan dibandingkan dengan nasi. Informan sering menyediakan stok mie instan untuk persediaan apabila dibutuhkan.

Faktor lingkungan makro. Lingkungan makro meliputi kebijakan kampus, norma sosial di masyarakat dan pengaruh iklan. Hasil wawancara 
menunjukkan bahwa tidak ada kebijakan di kampus mengenai makanan dan minuman yang sesuai dengan standar kesehatan ditunjang dengan ketiadaan inspeksi mengenai makanan dan minuman di kantin, serta promosi mengenai makanan sehat bagi mahasiswa menjadi salah satu faktor yang memengaruhi perilaku konsumsi mie instan pada mahasiswa.

"Itu tergantung menu yang mereka buat, tidak ada ketentuan dari kami.”

(A, pengelola kantin)

Faktor lain adalah beberapa daerah mempunyai kebiasaan untuk membagikan bungkusan berupa mie instan saat hajatan. Konsumsi mie instan merupakan hal yang biasa bagi masyarakat. Selain itu, iklan tidak terlalu berpengaruh terhadap pola konsumsi mie instan untuk varian rasa lama. Iklan lebih berpengaruh terhadap konsumsi mie instan varian rasa baru. Informan mengungkapkan ada rasa penasaran untuk mencoba mie instan varian rasa baru setelah melihat tayangan iklan di televisi.

\section{BAHASAN}

Berdasarkan hasil penelitian, didapatkan bahwa perilaku makan pada mahasiswa baik yang tinggal dengan orang tua maupun yang tinggal di kos mengalami perubahan pola makan, yang sebelumnya teratur menjadi tidak teratur serta berkurang. Hal ini dikarenakan jadwal perkuliahan yang sibuk pada awal masa perkuliahan. Perilaku makan mahasiswa dapat dipengaruhi oleh berbagai situasi secara fisik, seperti jadwal yang sibuk (13). Perubahan ini mengakibatkan mahasiswa cenderung memilih makanan yang praktis namun cenderung tidak sehat. Mahasiswa tidak lagi memperhatikan nilai gizi makanan yang dimakan. Mie instan adalah salah satu yang menjadi favorit mahasiswa (14).

Faktor individu yang memengaruhi perilaku makan merupakan karakteristik yang melekat pada diri individu, yang mempunyai pengaruh potensial yang cukup besar terhadap perilaku makan, termasuk perilaku makan sehat. Berdasarkan hasil penelitian, konsumsi mie instan oleh remaja dalam hal ini mahasiswa dipengaruhi oleh berbagai hal yang terkait dengan faktor individu, seperti rasa mie instan yang enak, aroma mie instan, praktis, agar bisa berhemat, kendala waktu dan hobi. Faktor individu lain yang mempunyai pengaruh terhadap konsumsi makanan adalah rasa dan selera terhadap suatu makanan (15).
Faktor individu seperti rasa dan persepsi terhadap makanan mempunyai pengaruh terhadap pilihan makan mahasiswa. Rasa mie instan yang enak serta ditunjang dengan aroma yang menggugah selera membuat mahasiswa tertarik untuk mengonsumsi mie instan dengan frekuensi yang cukup sering. Selain itu, aspek positif yang dinilai mahasiswa yakni mie instan lebih mudah untuk dimasak, murah, cepat, praktis tanpa harus meracik bumbu sendiri, sehingga tidak mengganggu aktivitas mahasiswa yang padat, sehingga membuat mie instan menjadi salah satu makanan favorit di kalangan mahasiswa (16). Kebiasaan mengonsumsi mie instan menjadi lebih intensif sejak kuliah dan tinggal di rumah kos, dikarenakan mie instan mudah, cepat, murah dan praktis. Konsumsi mie instan berkaitan dengan selera atau pilihan pribadi mahasiswa serta fungsi praktisnya (14).

Faktor individu lain yang memengaruhi konsumsi mie instan adalah dorongan rasa lapar. Beberapa informan mengungkapkan bahwa keinginan untuk mengonsumsi mie instan menjadi meningkat di saat sedang lapar dan tidak ada pilihan makanan lain untuk dikonsumsi. Alasan utama yang mendasari perilaku makan ataupun berhenti makan meliputi dorongan biologis berupa rasa lapar dan rasa kenyang, serta keinginan mencapai efek setelah makan (17).

Berdasarkan hasil penelitian, faktor individu lain yang memengaruhi mahasiswa mengonsumsi mie instan adalah pengetahuan dan sikap. Mahasiswa mengetahui bahaya mie instan serta menyatakan sikap tidak setuju terhadap konsumsi mie instan berlebihan. Namun, sulit untuk mengurangi konsumsi mie instan dikarenakan berbagai alasan lain yang mendorong mengonsumsi mie instan, seperti kendala keuangan dan waktu, praktis dan harga mie yang murah. Selain itu, beberapa mahasiswa juga pernah membuat aturan untuk membatasi konsumsi mie instan, antara lain dengan mengatur penyediaan stok mie instan. Mahasiswa mempunyai keyakinan dapat mematuhi aturan yang telah dibuat. Meskipun mahasiswa yakin dapat mematuhi aturan yang dibuat, namun keputusan mengonsumsi suatu makanan biasanya dipengaruhi faktor kesukaan dan besar uang saku (18).

Mie instan tetap menjadi pilihan di saat waktu yang tidak memungkinkan serta keuangan yang sedang menipis. Mahasiswa tidak terlalu mementingkan makanan yang sehat. Pilihan makanan sehat dapat menjadi prioritas rendah bila dibandingkan dengan komitmen lain, mahasiswa cenderung membeli makanan yang cepat, mudah dan murah. Mahasiswa lebih memprioritaskan kenyamanan dibandingkan dengan kesehatan (19). 
Faktor lingkungan sosial meliputi pola hubungan keluarga dan pola pertemanan mempunyai pengaruh terhadap konsumsi mie instan pada mahasiswa. Keluarga mempunyai peranan dalam membentuk selera pilihan makan mahasiswa. Mahasiswa cenderung mengikuti pola makan berdasarkan pola makan yang ada di dalam keluarga. Kontrol dari orang tua merupakan hal yang penting dalam hal ini, yang dapat memastikan pola makan sehat (20). Kebiasaan makan mahasiswa yang menjadikan keluarga sebagai kelompok acuan mempunyai peluang untuk memiliki kebiasaan makan yang lebih baik. Keluarga merupakan faktor utama dalam pembentukan pola perilaku makan dan juga pembinaan kesehatan. Keluarga memiliki peranan dalam mengendalikan kebiasaan makan mahasiswa (21).

Faktor lingkungan sosial lain, seperti pola pertemanan juga turut berpengaruh terhadap pola konsumsi mie instan. Beberapa mahasiswa mengaku mengonsumsi mie instan di saat sedang mengerjakan tugas bersama teman-teman serta ikut terpengaruh saat teman sedang makan mie instan di kantin. Rasa kebersamaan saat mengonsumsi mie instan menjadi salah satu alasan mahasiswa mengonsumsi mie instan. Pola pertemanan dapat memengaruhi kebiasaan makan mahasiswa, kemungkinan dapat dipengaruhi oleh ketersediaan waktu (21).

Perilaku konsumsi mie instan juga dipengaruhi oleh akses dan ketersediaan mie instan. Akses terhadap pilihan makan yang mudah merupakan salah satu pendorong perilaku makan pada remaja (22). Mahasiswa cenderung akan memilih makanan yang sehat apabila tersedia di kantin yang dekat dengan kampus. Penyediaan makanan sehat sangat diperlukan untuk menunjang perilaku makan yang sehat. Di sisi lain, kantin kampus yang menyediakan makanan yang tidak sehat dapat memengaruhi pilihan makan mahasiswa menjadi tidak sehat (23).

Faktor lingkungan makro dalam penelitian ini meliputi kebijakan yang berada di lingkungan kampus, norma sosial di masyarakat serta pengaruh iklan terhadap konsumsi mie instan pada mahasiswa. Ketiadaan kebijakan makanan dan minuman di kantin kampus menyebabkan mahasiswa bebas memilih makanan, yang mengakibatkan mahasiswa lebih memilih mengonsumsi makanan yang tidak sehat. Penyediaan makanan sehat di kantin kampus dapat berpengaruh terhadap pilihan makanan sehat untuk mahasiswa. Kantin kampus yang menyediakan produk makanan yang sehat berkontribusi terhadap perilaku makan lebih sehat pada mahasiswa (23).
Mahasiswa mengakui bahwa masyarakat sudah terbiasa mengonsumsi mie instan. Remaja mengonsumsi makanan cepat saji jika remaja mempersepsikan bahwa keluarga dan masyarakat mengonsumsi makanan tersebut juga (24). Hal ini juga tidak terlepas dari pengaruh iklan, baik iklan di televisi maupun iklan pada banner. Beberapa informan mengakui bahwa menjadi tertarik untuk mencoba mie varian baru. Rasa penasaran menjadi dorongan utama mahasiswa mencoba mie instan varian baru. Di sisi lain, mahasiswa tidak terlalu terpengaruh iklan untuk mengonsumsi mie instan. Iklan merupakan faktor yang berpengaruh kecil terhadap pilihan makan. Faktor utama pilihan makan yakni rasa dan efek samping kesehatan, yang diikuti dengan faktor gaya hidup seperti harga makanan, kenyamanan, namun faktor iklan memegang peranan yang rendah terhadap pilihan makan (16).

Mahasiswa juga menyarankan promosi kesehatan terutama pola makan sehat melalui seminar, yang sebelumnya telah disosialisasikan terlebih dahulu. Seminar sebaiknya dilakukan per jurusan agar lebih efektif. Namun, seminar yang diadakan hendaknya tidak terlalu banyak menggunakan slide power point, tetapi lebih banyak praktik seperti demo masak. Selain itu, promosi kesehatan melalui media sosial yang sedang diminati oleh mahasiswa, antara lain instagram, dengan membuat gambar lucu yang menarik minat mahasiswa untuk membaca pesan kesehatan yang akan disampaikan. Media sosial saat ini menjadi salah satu sarana yang dapat digunakan untuk melakukan sosialisasi mengenai pola makan sehat, hal ini dikarenakan perubahan kebiasaan masyarakat sekarang yang lebih banyak menghabiskan waktu bersosialisasi melalui media ssosial. media sosial mempunyai pengaruh yang cukup tinggi untuk mempromosikan pola makan sehat. Pendidik- an kesehatan dapat dilakukan dengan menyebarkan informasi kesehatan dan melakukan komunikasi melalui media sosial (25).

Perlu adanya kebijakan mengenai makanan dan minuman yang diperbolehkan dijual di kampus agar dapat membuat pilihan makanan yang sehat bagi mahasiswa. Lingkungan makan di sekolah mempunyai dampak yang besar terhadap pilihan dan kualitas makan, karena remaja mengonsumsi proporsi total energi yang besar dari total energi harian yang dibutuhkan di sekolah. Perilaku makan dapat dipengaruhi oleh lingkungan kampus, salah satunya adalah kebijakan kampus (15). 


\section{SIMPULAN}

Konsumsi mie instan meningkat pada saat awal masuk kuliah. Kepadatan aktivitas jadwal kuliah menyebabkan mahasiswa lebih memilih mengonsumsi mie instan. Faktor yang paling memengaruhi konsumsi mie instan pada mahasiswa adalah faktor individu, meliputi kendala waktu, harga, tingkat kepraktisan, rasa lapar, rasa mie instan yang enak, dan aroma yang khas serta faktor hobi.

Konsumsi mie instan yang meningkat sejak kuliah dipengaruhi oleh tidak ada kebijakan mengenai makanan dan minuman yang dijual di kampus, serta tidak adanya inspeksi makanan dan minuman, dan upaya promosi pada mahasiswa. Selain itu, kebiasaan di masyarakat mengonsumsi juga turut berpengaruh terhadap konsumsi mie instan. Di samping itu, peran media turut berkontribusi terhadap konsumsi mie instan varian rasa baru, namun untuk varian mie instan rasa lama, iklan di televisi tidak terlalu berpengaruh. Mahasiswa juga memberikan saran untuk upaya promosi melalui seminar dengan lebih banyak praktek serta melalui media sosial yang sedang populer saat ini

Saran-saran pada penelitian ini adalah melakukan upaya promosi kesehatan yakni dengan melakukan seminar yang lebih banyak praktik serta menyebarkan informasi melalui media sosial yang sedang populer saat ini. Selain itu, dapat juga dengan melakukan upaya advokasi kepada pihak kampus agar dapat membentuk kebijakan terkait makanan dan minuman yang dijual di kampus, melakukan inspeksi ataupun pengecekan makanan dan minuman yang dijual di kantin kampus serta menyediakan fasiltas kantin yang sehat agar dapat memberikan pilihan makan sehat bagi mahasiswa, serta agar mahasiswa membatasi konsumsi makanan yang tidak sehat.

\footnotetext{
Abstrak

Tujuan: Penelitian ini bertujuan untuk menggali gambaran faktor yang memengaruhi perilaku konsumsi mie instan pada mahasiswa universitas Sriwijaya. Metode: Penelitian kualitatif dengan pendekatan fenomenologi. Pengumpulan data dilakukan dengan wawancara mendalam pada 20 informan. Teknik pengambilan sampel dengan purposive sampling. Pengumpulan data dilakukan pada bulan Juni sampai September 2015. Hasil: Penelitian menunjukkan faktor individu merupakan faktor yang paling berpengaruh meliputi kendala waktu,
}

rasa, aroma, harga didukung dengan faktor lingkungan sosial yang meliputi pola hubungan keluarga dan pola pertemanan. Faktor lingkungan fisik meliputi akses yang mudah dan ketersediaan mie instan yang mencukupi serta faktor lingkungan makro meliputi tidak adanya kebijakan kampus, norma sosial di masyarakat serta iklan berpengaruh terhadap konsumsi mie instan varian rasa baru. Simpulan: Mahasiswa memberikan saran upaya promosi melalui seminar dan media sosial.

Kata kunci: konsumsi mie instan; mahasiswa

\section{PUSTAKA}

1. World Health Organization. Noncommunicable Diseases. 2015.

2. Centers for Disease Control and Prevention. Get The Fact: Sodium's Role in Processed Food. 2012.

3. Park J, Lee JS, Jang YA, Chung HR, Kim J. A comparison of food and nutrient intake between instant noodle consumers and non-instant noodle consumers in Korean adults. Nutrition research and practice. 2011 Oct 1;5(5):443-9.

4. Lee JE, Kim JH, Son SJ, Ahn Y, Lee J, Park C, Lee L, Erickson KL, Jung IK. Dietary pattern classifications with nutrient intake and health-risk factors in Korean men. Nutrition. 2011 Jan 1;27(1):26-33.

5. Shin HJ, Cho E, Lee HJ, Fung TT, Rimm E, Rosner B, Manson JE, Wheelan K, Hu FB. Instant Noodle Intake and Dietary Patterns Are Associated with Distinct Cardiometabolic Risk Factors in Korea-. The Journal of nutrition. 2014 Jun 25;144(8):1247-55.

6. Chung CE, Lee KW, Cho MS. Noodle consumption patterns of American consumers: NHANES 2001-2002. Nutrition research and practice. 2010 Jun 1;4(3):243-51.

7. Gulia N, Dhaka V, Khatkar BS. Instant noodles: Processing, quality, and nutritional aspects. Critical reviews in food science and nutrition. 2014 Jan 1;54(10):1386-99.

8. World Instant Noodles Association. Global demand on instant noodles. 2014.

9. Susenas. Pengeluaran untuk Konsumsi Penduduk Indonesia. Jakarta. 2013.

10. Badan Penelitian dan Pengembangan. Riset Kesehatan Dasar. Jakarta. 2013.

11. El Ansari W, Stock C, Mikolajczyk RT. Relationships between food consumption and living arrangements among university students in four European countries-a cross-sectional study. Nutrition journal. 2012 Dec;11(1):28.

12. Story M, Neumark-Sztainer D, French S. Individual and environmental influences on adolescent eating behaviors. Journal of the Academy of Nutrition and Dietetics. 2002 Mar 1;102(3):S40-51.

13. Arnold TA, Johnston CS, Lee CD, Garza AM. Eating in the absence of hunger in college students. Appetite. 2015 Sep 1;92:51-6.

14. Arianto NT. Pola Makan Mie Instan: Studi Antropologi Gizi Pada Mahasiswa. Surabaya. 2011.

15. Taylor JP, Evers S, McKenna M. Determinants of 
16. healthy eating in children and youth. Canadian Journal of Public Health/Revue Canadienne de Sante'e Publique. 2005 Jul 1:S20-6.

17. Soyer MT, Ergin I, Gursoy ST. Effects of social determinants on food choice and skipping meals among Turkish adolescents. Asia Pacific journal of clinical nutrition. 2008 Jun 1;17(2):208-15.

18. Dewi TR. Studi Deskriptif: Perilaku Makan pada Mahasiswa Universitas Surabaya. Calyptra. 2014;3(2):1-15.

19. Adriani M, Wirjatmadi B. Peranan gizi dalam siklus kehidupan. In: Pertama. Jakarta: Kencana Prenada Media Group; 2012.

20. Nelson MC, Kocos R, Lytle LA, Perry CL. Understanding the perceived determinants of weight-related behaviors in late adolescence: a qualitative analysis among college youth. Journal of nutrition education and behavior. 2009 Jul 1;41(4):287-92.

21. Stevenson C, Doherty G, Barnett J, Muldoon OT, Trew K. Adolescents' views of food and eating:
Identifying barriers to healthy eating. Journal of adolescence. 2007 Jun 1;30(3):417-34.

22. Saufika A, Retnaningsih A, Alfiasari A. Gaya hidup dan kebiasaan makan mahasiswa. Jurnal Ilmiah Keluarga. 2012 Aug 1;5(2):157-65.

23. Story M, Neumark-Sztainer D, French S. Individual and environmental influences on adolescent eating behaviors. Journal of the Academy of Nutrition and Dietetics. 2002 Mar 1;102(3):S40-51.

24. Deliens T, Clarys P, De Bourdeaudhuij I, Deforche B. Determinants of eating behaviour in university students: a qualitative study using focus group discussions. BMC public health. 2014 Dec;14(1):53.

25. Pelletier JE, Graham DJ, Laska MN. Social norms and dietary behaviors among young adults. American journal of health behavior. 2014 Jan 1;38(1):144-52.

26. Leis Á, Mayer MÁ, Torres Niño J, Rodríguez-González A, Suelves JM, Armayones M. Healthy eating support groups on Facebook: content and features. Gaceta sanitaria. 2013 Aug;27(4):355-7. 
